\title{
Alumina-Promoted Sulfated Mesoporous Zirconia Catalysts
}

\author{
Chi-Chau Hwang ${ }^{\dagger}$ and Chung-Yuan Mou*,;,*亠 \\ Department of Chemistry, National Taiwan University, Taipei 106, Taiwan, and Center of Condensed Matter \\ Science, National Taiwan University, Taipei 106, Taiwan
}

Received: November 28, 2008; Revised Manuscript Received: January 23, 2009

\begin{abstract}
Mesoporous zirconia, hydrothermally synthesized from surfactant templating, was directly impregnated with aluminum sulfate to give the acidic Al-promoted sulfated mesoporous zirconia (AS/MP- $\mathrm{ZrO}$ ). A series of AS/MP- $-\mathrm{ZrO}_{2}$ catalysts were characterized by Brunauer-Emmett-Teller and X-ray diffraction for their texture properties and crystalline phases. The catalytic behavior for $n$-butane isomerization was found to be strongly promoted at relatively low temperature by the addition of a proper amount of alumina as a promoter. ${ }^{27} \mathrm{Al}$ S.S. magic-angle spinning nuclear magnetic resonance results indicated that $\mathrm{Zr}$ atoms were partially substituted by $\mathrm{Al}$, giving a considerable increased concentration of Brønsted acids. X-ray photoelectron spectroscopy and diffuse-reflectance infrared Fourier-transformed spectra (DRIFT) analysis were then employed to identify and relatively quantify properties of acid sites on catalyst surface. A balanced distribution of acid sites strength was proven to prevent a catalyst from deactivating rapidly due to coke formation on the catalyst surface. A small concentration of olefins formed by oxidation of $n$-butane and proven to be key intermediates during $n$-butane isomerization on sulfated zirconia was found by the Baeyer test. Electron paramagnetic resonance and in situ DRIFT results show that this occurs via oxidative dehydrogenation of butane by the sulfate groups to form butene which leads to butyl carbenium species for skeleton isomerization. A modified biomolecular mechanism for the isomerization of butane is examined to explain the catalysis results.
\end{abstract}

\section{Introduction}

Since the discovery of its strong acidity, sulfated zirconia (SZ) has attracted much attention as a promising process catalyst. The main interest is associated with increasing need for environmentally benign catalysts and reaction processes. SZ is a solid acid catalyst with great potential application in industrial acid-catalyzed processes, such as the skeleton isomerization of alkanes ${ }^{1,2}$ and esterification in biodiesel production. ${ }^{3}$ It is a good substitute for the conventional liquid-phase or halidecontaining solid acid catalysts that have caused much environmental concerns.

Initially, Arata and co-workers devoted their attention to the preparation of SZ, its physicochemical properties, and catalytic performance in alkane isomeriation at relatively mild temperatures. ${ }^{1,2}$ But SZ catalysts suffer from the disadvantages of deactivation and possibly from sulfur loss during reaction and regeneration. Later, SZ catalysts have been successfully incorporated with transition metals ( $\mathrm{Fe}$ and $\mathrm{Mn})^{4}$ so as to enhance substantially its catalytic performance in $n$-alkane isomerization reactions. In spite of the high catalytic activity and product selectivity achieved by Fe/Mn-promoted SZ, serious concerns about the long-term stability still remain and cast doubt on its industrial applications. Thus, the noble metal Pt often has to be used to stabilize the catalytic activity. ${ }^{5}$ Then, one would have a drawback in Pt-promoted SZ catalyst that it is sensitive to sulfur in the feed gas.

Lately, the promotion effect of main group metals (alumina or gallium) ${ }^{6,7}$ on SZ in the isomerization reaction of $n$-alkanes has received much attention for it stabilized and promoted activity

* To whom correspondence should be addressed. E-mail: cymou@ ntu.edu.tw.

$\dagger$ Department of Chemistry, National Taiwan University.

* Center of Condensed Matter Science, National Taiwan University. without the use of $\mathrm{Pt}^{8-13}$ We reported that the addition of an optimum amount of $\mathrm{Al}$ onto the SZ catalyst, in various morphologies, gives rise to a catalyst much more active than the corresponding unpromoted one. ${ }^{14,15}$ These promotional effects have been demonstrated on the isomerization reactions of butane, ${ }^{16}$ pentane,${ }^{13}$ and hexane. ${ }^{11}$ The promotion and stabilization effects of $\mathrm{Al}$ on SZ in alkane isomerization without the use of expensive $\mathrm{Pt}$ are technologically encouraging. We are thus developing a new generation of catalyst for alkane isomerization.

In the past, the main active site of $\mathrm{SZ}$ for the catalytic isomerization of alkane is considered to be the acid sites, although there have been debates about the relative importance of Brønsted vs Lewis acid sites. However, recently there has been a change of our understanding in the catalytic mechanism of SZ. SZ catalyst not only plays the role of solid acid, but also it was shown to initiate the catalytic cycle by dehydrogenation to olefin which then forms carbine for the chain initiation. ${ }^{17,18}$ The redox property of SZ is responsible for the oxidative dehydrogenation. In our previous work, ${ }^{14}$ we have been focusing the role of $\mathrm{Al}$ on the acidity SZ. So in view of the recent work on redox property of SZ, we should come to understand the role of $\mathrm{Al}$ also in the promotion of redox reaction.

In this work, alumina-promoted sulfated mesoporous zirconia catalysts (named as $\mathrm{AS} / \mathrm{MP}-\mathrm{ZrO}_{2}$ ) were used to investigate the catalytic behavior of $n$-butane isomerization reaction. Sulfated mesoporous zirconia ( $\mathrm{S} / \mathrm{MP}-\mathrm{ZrO}_{2}$ ) was first successfully synthesized in $1999^{19}$ and was tested for $n$-alkane isomerization. ${ }^{20}$ As it has relatively high surface area, one would expect a better catalytic performance over the low surface area SZ catalysts. ${ }^{21}$

In addition to the information about identifying Brønsted and Lewis acid sites ${ }^{22}$ on the catalyst after chemisorption of probe molecules, various characterization techniques, such as electron paramagnetic resonance (EPR), in situ diffuse-reflectance infrared Fourier-transformed spectra (DRIFTs), and olefin 
titration with aqueous potassium permanganate $\mathrm{KMnO}_{4}$ (Baeyer test), were employed to reveal the role of $\mathrm{Al}$ in the promotion of redox reaction. Our primary goal is to understand the origin and function of the catalytic active sites, and this information will in turn help us in optimizing the composition of aluminum and sulfur for a better performing catalyst.

\section{Experimental Section}

2.1. Catalyst Preparation. The mesoporous $\mathrm{ZrO}_{2}\left(\mathrm{MP}-\mathrm{ZrO}_{2}\right)$ was synthesized by the surfactant-assisted route, as in the previous report of Ciesla et al.. ${ }^{19}$ An ordered $\mathrm{MP}-\mathrm{ZrO}_{2}$ material loaded with aluminum sulfate (Hayashi Osaka, denoted as $x \mathrm{AS} /$ $\mathrm{MP}-\mathrm{ZrO}_{2}$ with $x$ corresponding to the nominal AS concentration in wt $\%$ based on the amount of $\mathrm{MP}-\mathrm{ZrO}_{2}$ ), aluminum nitrate (Acros, A/MP-ZrO ${ }_{2}$ ), and ammonium sulfate (Acros, S/MP$\mathrm{ZrO}_{2}$ ) was prepared via incipient wetness impregnation: the required quantity of each source dissolved in $75 \%$ (vol \%) alcohol solution was impregnated by the as-synthesized mesophase zirconia-containing surfactant. The slurry was stirred for $5 \mathrm{~h}$ and oven-dried at $100{ }^{\circ} \mathrm{C}$ overnight. All the catalysts were calcined at $400{ }^{\circ} \mathrm{C}$ for $5 \mathrm{~h}$ to eliminate the template and then at $630{ }^{\circ} \mathrm{C}$ for $5 \mathrm{~h}$ to obtain the tetragonal phase of zirconia (in static air with a heating ramp of $3{ }^{\circ} \mathrm{C} / \mathrm{min}$ ).

2.2. Characterization Techniques. Elemental analysis was determined by inductively coupled plasma atomic emission spectroscopy (ICP-AES) using a Jarrel-Ash ICAP 9000 instrument. Carbon analysis was done with a Heraeus VarioEL-III instrument.

In situ diffuse-reflectance infrared Fourier-transformed (DRIFT) spectra of ammonia chemisorbed on catalyst were taken with a Thermo Nicolet 380 FTIR spectrometer. The sample was first dried at $400{ }^{\circ} \mathrm{C}$ for at least $1 \mathrm{~h}$ prior to ammonia adsorption. The adsorption of ammonia was done by flowing $5 \% \mathrm{NH}_{3} / \mathrm{N}_{2}$ mixture through the catalyst at $120^{\circ} \mathrm{C}$ for $5 \mathrm{~min}$, and the system was then flushed with dry $\mathrm{N}_{2}$ for $15 \mathrm{~min}$. The catalyst with adsorbed ammonia was then subjected to a desorption process at increasing temperatures. Spectra were recorded after the catalyst's temperature was held for $15 \mathrm{~min}$ at each temperature. The similar methodology was also applied to adsorb butane on the activated sample at $50{ }^{\circ} \mathrm{C}$.

$\mathrm{X}$-ray photoelectron spectroscopic (XPS) analysis of pyridine chemisorbed on catalyst was performed using a Thermo VG Scientific ESCALAB 250 instrument with a monochromatic Al $\mathrm{K} \alpha$ radiation $(1486.8 \mathrm{eV})$ and under a residual pressure of $\sim 5$ $\times 10^{-10}$ torr. The pyridine-adsorbed sample was first degassed ex situ under vacuum at about $120{ }^{\circ} \mathrm{C}$ for $0.5 \mathrm{~h}$. The pretreated sample was then transferred into the XPS instrument, and spectra were collected in the $\mathrm{N} 1 \mathrm{~s}$ region. Charge effects were compensated by electron flux from a flooding gun, and the $\mathrm{Zr}$ $3 \mathrm{~d}_{5 / 2}$ binding energy was set at $182.2 \mathrm{eV}$. The spectral profiles were deconvoluted into peaks by using XPSPEAK software from RCSMS laboratory.

The Baeyer test-a conventional method to check the oxidation of alkenes with aqueous potassium permanganate $\left(\mathrm{KMnO}_{4}\right)$-was adopted to check certain unsaturated olefin species produced during the $n$-butane isomerization. The reaction gases exiting the reactor were passed through a potassium permanganate aqueous solution with $5 \mathrm{~mL}$ of $0.5 \mu \mathrm{M}$, and the time-dependent UV - vis experiment was monitored by a Hitachi U-3310 spectrophotometer.

The solid-state ${ }^{27} \mathrm{Al}$ MAS NMR spectra were taken to determinate the coordination states of aluminum. The experiments were performed at room temperature on a Bruker DSX400WB NMR spectrometer with a 4 mm-diameter $\mathrm{ZrO}_{2}$ rotor spun at $4.0 \mathrm{kHz}$ at $9.4 \mathrm{~T}$ magnetic field.
EPR spectra were obtained at 84 and $300 \mathrm{~K}$ with a Bruker EMX spectrometer working in the X-band $(9.53 \mathrm{GHz})$. A weighted catalyst of $0.2 \mathrm{~g}$ was placed inside a 4-mm outside diameter quartz tube with stopcocks. Prior to each measurement, the catalysts were evacuated at room temperature below $1 \times$ $10^{-3}$ Torr.

2.3. Catalytic Study. Catalytic reaction was carried out in a fixed bed continuous flow quartz reactor at atmospheric pressure. The catalyst (usually $1.0 \mathrm{~g}$ ) was first pressed into 10-20 mesh size pellets and mixed with quartz sand. It was then pretreated under an air flow at $450{ }^{\circ} \mathrm{C}$ for $3 \mathrm{~h}$ and then prereduced with $\mathrm{H}_{2}$ at $300{ }^{\circ} \mathrm{C}$ for $1 \mathrm{~h}$. After flushing the system with $\mathrm{N}_{2}$ at the reaction temperature for $0.5 \mathrm{~h}$, the reaction was started by introducing a mixture of $n$-butane ( $\geq$ U99.9\%, Sanfu) and $\mathrm{H}_{2}\left(n-\mathrm{C}_{4}: \mathrm{H}_{2}=1: 10 \mathrm{v} / \mathrm{v}\right)$ at a total inlet flow rate of $15.5 \mathrm{~mL} \mathrm{~min}^{-1}$. The reaction product was analyzed by an online Agilent $6890 \mathrm{~N}$ gas chromatograph equipped with a flame ionization detector and a 60-m DB-1 column.

\section{Results}

3.1. Structure Study. Before we present the catalytic properties of alumina-promoted $\mathrm{AS} / \mathrm{MP}-\mathrm{ZrO}_{2}$, we would like to have definite information about their textual properties. In addition, the thermal stability of crystalline phase and surface features such as surface acidity and redox property of these sulfated mesoporous zirconia catalysts promoted by alumina were also studied.

Textural properties of various sulfated mesoporous zirconia catalysts with or without alumina (i.e., AS/MP- $\mathrm{ZrO}_{2}$ or S/MP$\mathrm{ZrO}_{2}$ ) were characterized by $\mathrm{X}$-ray diffraction and $\mathrm{N}_{2}$ adsorptiondesorption isotherm. In Figure 1a, X-ray diffraction patterns for the $2 \mathrm{AS} / \mathrm{MP}-\mathrm{ZrO}_{2}$ and $2 \mathrm{~S} / \mathrm{MP}-\mathrm{ZrO}_{2}$ catalysts exhibited a single broad peak at $\sim 1.0^{\circ}$ due to their somewhat disordered mesostructure. From TEM images, we found that its mesostructures are of wormlike nanopores. ${ }^{15}$ For the $\mathrm{MP}-\mathrm{ZrO}_{2}$ sample without alumina or sulfate dopants, the low-angle XRD peak shows a less-ordered mesostructure suggesting collapse of its nanochannels. The high angle region of XRD peaks of these three catalysts (Figure 1b) are characteristic of the tetragonal crystalline phase (demoted as $\mathrm{T}$ ) of $\mathrm{ZrO}_{2}$ which is the active phase for the catalysis of alkane isomerization. ${ }^{8}$ It is worth noting that the $2 \mathrm{AS} / \mathrm{MP}-\mathrm{ZrO}_{2}$ catalyst can maintain not only better mesostructure of zirconia but also retard the crystalline transformation from tetragonal to monoclinic phase (demoted as $\mathbf{M}$ in Figure 1a). The Brunauer-Emmett-Teller isotherms of these three samples (Figure 1c) with the hysteresis between adsorption and desorption branches are typical for a mesoporous material. Apparently, considerable loss of the volume of $\mathrm{N}_{2}$ adsorbed in $2 \mathrm{~S} / \mathrm{MP}-\mathrm{ZrO}_{2}$ and $\mathrm{MP}-\mathrm{ZrO}_{2}$ catalysts also indicates some collapse of their mesoporous structure. This observation of structural instability is consistent with the XRD result for samples with calcination temperature at $630{ }^{\circ} \mathrm{C}$. Compared to $2 \mathrm{~S} / \mathrm{MP}-\mathrm{ZrO}_{2}$ and $\mathrm{MP}-\mathrm{ZrO}_{2}$ catalysts, Figure 1d then depicts that a more homogeneous pore size distribution with a sharper peak centered at $3.3 \mathrm{~nm}$ found on the alumina-promoted catalyst 2AS/MP$\mathrm{ZrO}_{2}$.

3.2. Catalytic Reaction. Butane isomerization reaction is a valuable model reaction for understanding the skeleton isomerization of alkanes catalyzed by strong solid acid such as SZ. ${ }^{23}$ It is interestingly complex enough to show both the roles of acidity and redox properties of the catalyst. To understand the individual role played by $\mathrm{Al}$ and $\mathrm{S}$ in the catalytic reaction, we tried to fine-tune the composition of the AS/MP- $\mathrm{ZrO}_{2}$ catalyst with an additional small amount of sulfate or alumina. The 


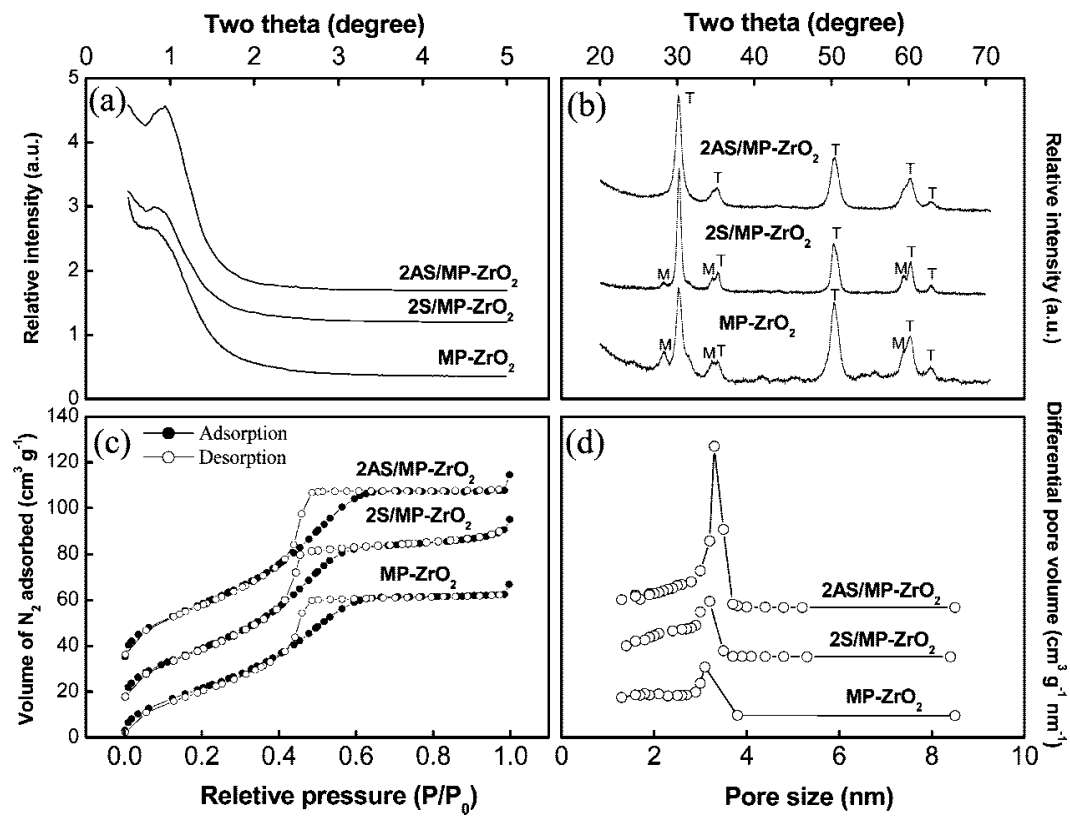

Figure 1. XRD patterns, $\mathrm{N}_{2}$ adsorption-desorption isotherm, and pore size distribution for $\mathrm{MP}-\mathrm{ZrO}_{2}, 2 \mathrm{~S} / \mathrm{MP}-\mathrm{ZrO}{ }_{2}$, and $2 \mathrm{AS} / \mathrm{MP}-\mathrm{ZrO}{ }_{2}$ catalysts calcined at $630^{\circ} \mathrm{C}$.

TABLE 1: Elemental Analysis, Texture Properties, and Performance of Selected Sulfated Mesoporous Zirconia-Supported Catalysts in $n$-Butane Isomerization Reaction at $250{ }^{\circ} \mathrm{C}$

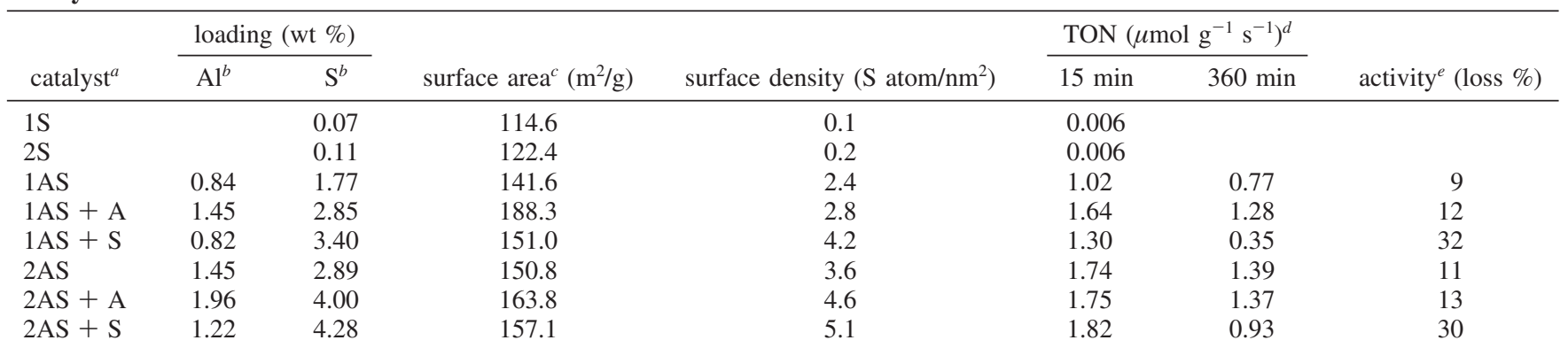

${ }^{a}$ Catalysts used mesoporous zirconia $\left(\mathrm{MP}-\mathrm{ZrO}_{2}\right)$ as support. ${ }^{b}$ Determined from ICP-AES and EA. ${ }^{c}$ Determined from $\mathrm{N}_{2}$ adsorption-desorption isotherm at $77 \mathrm{~K} .{ }^{d}$ Turnover number, which is the number of micromoles of $n$-butane converted per gram of catalyst per second at $250{ }^{\circ} \mathrm{C} .{ }^{e}$ Defined by variation of butane conversion at time on stream between $15 \mathrm{~min}$ and $360 \mathrm{~min}$.

catalysts are hereafter labeled as $x \mathrm{AS} / \mathrm{MP}-\mathrm{ZrO}_{2}, x \mathrm{AS}+\mathrm{A} / \mathrm{MP}-$ $\mathrm{ZrO}_{2}$, or $x \mathrm{AS}+\mathrm{S} / \mathrm{MP}-\mathrm{ZrO}_{2}$ with $x$ corresponding to the nominal aluminum sulfate concentration in wt \% based on the MP- $\mathrm{ZrO}_{2}$ and $\mathrm{A}$ or $\mathrm{S}$ corresponding to the extra fixed concentration of nominal aluminum or sulfate based on the total sample weight. The elemental composition of these catalysts and their corresponding catalytic activities for $n$-butane isomerization reaction were summarized in Table 1. For detailed time-dependence behavior, the conversions vs time-on-stream are shown in Figure 2. An important finding in our elemental analysis study is that the amount of $\mathrm{Al}$ loaded onto the catalyst has a direct influence on the amount of $\mathrm{S}$ in the catalyst. The use of ammonium sulfate is superior over other methods of sulfation of zirconia, ${ }^{24}$ while the addition of aluminum in the form of aluminum sulfate increases much the loading of sulfur. This observation is apparent by comparing the $\mathrm{S}$ loading of catalysts $2 \mathrm{AS} / \mathrm{MP}-\mathrm{ZrO}_{2}$ and $2 \mathrm{AS}+\mathrm{A} / \mathrm{MP}-\mathrm{ZrO}_{2}$ or $1 \mathrm{AS} / \mathrm{MP}-\mathrm{ZrO}_{2}$ and $1 \mathrm{AS}+\mathrm{A} / \mathrm{MP}-\mathrm{ZrO}{ }_{2}$. The correlation in the loadings of $\mathrm{Al}$ and $\mathrm{S}$ in these catalysts hinted that there are some kinds of interaction between them. An increase of $\mathrm{Al}$ content leads a large increase of $\mathrm{S}$ content.

The best performing catalysts are $2 \mathrm{AS}+\mathrm{A} / \mathrm{MP}-\mathrm{ZrO}_{2}$ and $2 \mathrm{AS} /$ $\mathrm{MP}-\mathrm{ZrO}{ }_{2}$ with their $n$-butane conversion reaching about $60 \%$ $\left(\mathrm{TON} \approx 1.75 \mu \mathrm{mol} \mathrm{g}^{-1} \mathrm{~s}^{-1}\right.$ ) at $250{ }^{\circ} \mathrm{C}$ (Figure 2). In addition, the selectivity of main product, isobutane, for these catalysts

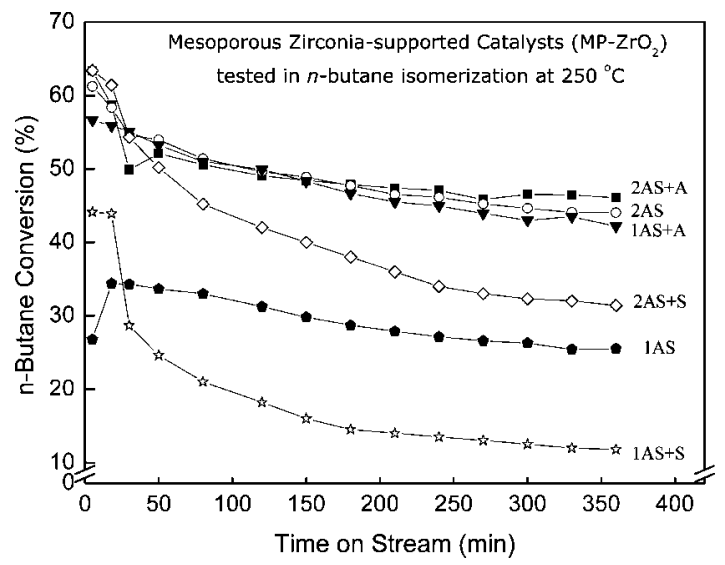

Figure 2. Catalytic profiles of mesoporous zirconia-supported catalysts in $n$-butane isomerization reaction at $250{ }^{\circ} \mathrm{C}$. The ratio of $n$-butane: $\mathrm{H}_{2}$ is $1: 10(\mathrm{~V}: \mathrm{V})$ at a total inlet flow rate of $15.5 \mathrm{~mL} / \mathrm{min}$ and $1 \mathrm{~atm}$.

was higher than $85 \%$ while small amounts of methane, propane, and pentane were also observed.

The time evolution of activity shows general decay to steady activity from initial high conversions with two characteristics: (1) larger deactivation when excess sulfur was present (1AS + $\mathrm{S}$ and $2 \mathrm{AS}+\mathrm{S}$ ), and (2) more steady behavior in conversion 


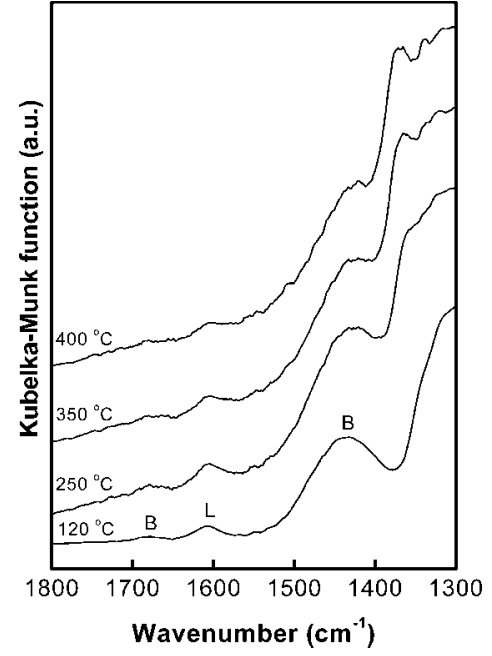

Figure 3. DRIFT spectra of the adsorption of $\mathrm{NH}_{3}$ at $120^{\circ} \mathrm{C}$ on $2 \mathrm{AS} /$ $\mathrm{MP}-\mathrm{ZrO}_{2}$ catalyst and followed by desorption at $250,350,400{ }^{\circ} \mathrm{C}$. (B $=$ Brønsted acid sites; $\mathrm{L}=$ Lewis acid sites.)

when excess aluminum was added (1AS $+\mathrm{A}$ and $2 \mathrm{AS}+\mathrm{A})$. The initial (at $15 \mathrm{~min}$ ) and steady (at $360 \mathrm{~min}$ ) activities are listed in Table 1.

3.3. Acidity of the Catalysts and Promotion Effect of Al. To measure the acidity of SZ catalyst, we used ammonia as the probe molecule. In situ ammonia adsorption-desorption measurements describe the acidity of solid acids with oxidative power such as SZ catalyst. ${ }^{25,26}$ Carbon-containing base probes such as pyridine would have been oxidized by SZ at moderately high temperature. Figure 3 illustrates the in situ DRIFT spectra for $2 \mathrm{AS} / \mathrm{MP}-\mathrm{ZrO}_{2}$ catalyst after treatment of surface-adsorbed $\mathrm{NH}_{3}$ at different temperatures. Two types of acid sites were found on this catalyst, namely, the Brønsted acid sites (B) and Lewis acid sites (L). The band at $1609 \mathrm{~cm}^{-1}$ corresponds to the asymmetric $\mathrm{N}-\mathrm{H}$ deformation mode $\left(\delta_{\mathrm{as}}\right)$ of $\mathrm{NH}_{3}$ coordinated to the Lewis acid sites. ${ }^{27}$ Another intense band at $1428 \mathrm{~cm}^{-1}$ and the weak band at $1675 \mathrm{~cm}^{-1}$ correspond to the $\delta_{\mathrm{s}}$ and $\delta_{\text {as }}$ of $\mathrm{NH}_{4}{ }^{+}$formed on the Brønsted acid sites, respectively. ${ }^{27}$ The bands in the region below $1373 \mathrm{~cm}^{-1}$ are mainly due to the lattice vibration of $\mathrm{MP}-\mathrm{ZrO}_{2}$. All the bands due to adsorbed $\mathrm{NH}_{3}$ decreased in intensity at increasing desorption temperatures, indicating the loss of $\mathrm{NH}_{3}$ adsorbed on these acid sites. The strength of the Brønsted acid sites in $2 \mathrm{AS} / \mathrm{MP}-\mathrm{ZrO}_{2}$ catalyst seems to be stronger than that of Lewis acid sites since there are relatively more $\mathrm{NH}_{3}$ molecules remaining adsorbed on the Brønsted acid sites at $400{ }^{\circ} \mathrm{C}$.

${ }^{27} \mathrm{Al}$ MAS NMR technique is used to study the coordination environment of Al. Here, this technique is employed to study the relationship between the acid sites and $\mathrm{Al}$ species on 2AS/ $\mathrm{MP}-\mathrm{ZrO}_{2}$ catalyst before and after calcination. The ${ }^{27} \mathrm{Al}$ MAS NMR spectra of $2 \mathrm{AS} / \mathrm{MP}-\mathrm{ZrO}_{2}$ catalyst are shown in Figure 4. $\mathrm{Al}_{2}\left(\mathrm{SO}_{4}\right)_{3}$ and $\mathrm{Al}_{2} \mathrm{O}_{3}$ were used as external standards for comparison. The spectrum of uncalcined catalyst 2AS/MP$\mathrm{ZrO}_{2}$ (UC) consists of a broader resonance between 30 and -60 ppm centered at $\sim 0 \mathrm{ppm}$, which is assigned to $\mathrm{Al}$ in octahedral sites. The signal for calcined sample $2 \mathrm{AS} / \mathrm{MP}-\mathrm{ZrO}_{2}$ is apparently sharper than that for $2 \mathrm{AS} / \mathrm{MP}-\mathrm{ZrO}_{2}(\mathrm{UC})$ due to its more homogeneous chemical environment of octahedral $\mathrm{Al}$ species. Besides, the minor resonance center at $\sim 30 \mathrm{ppm}$ in the spectrum of $2 \mathrm{AS} / \mathrm{MP}-\mathrm{ZrO}_{2}$ has been reported for aluminum in 5-fold coordination in oxo complexes between 30 to $40 \mathrm{ppm}^{29}$

The sample $2 \mathrm{~A} / \mathrm{MP}-\mathrm{ZrO}_{2}$ was prepared in a manner similar to $2 \mathrm{AS} / \mathrm{MP}-\mathrm{ZrO}_{2}$ but using aluminum nitrate in place of
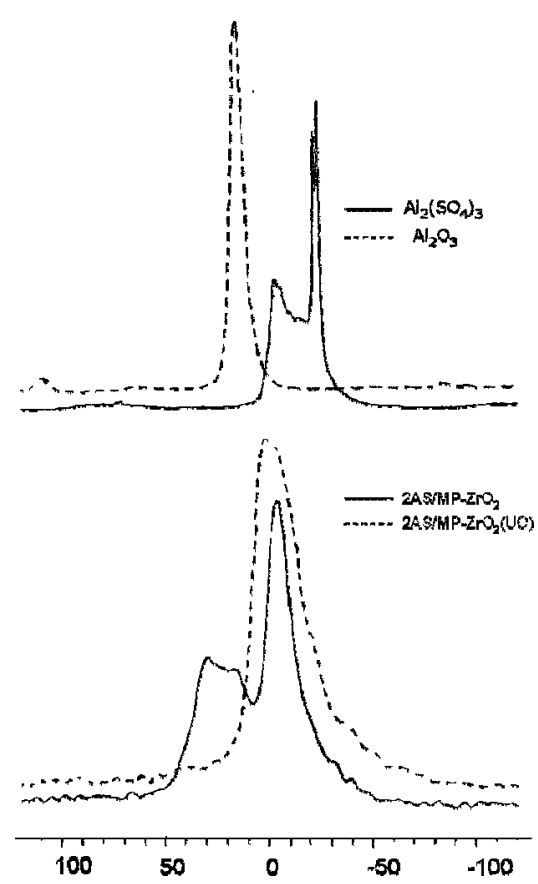

Figure 4. ${ }^{27} \mathrm{Al}$ MAS NMR spectra of $2 \mathrm{AS} / \mathrm{MP}-\mathrm{ZrO}_{2}$ catalyst before and after calcination. $\mathrm{Al}_{2}\left(\mathrm{SO}_{4}\right)_{3}$ and $\mathrm{Al}_{2} \mathrm{O}_{3}$ were standard samples for comparison.

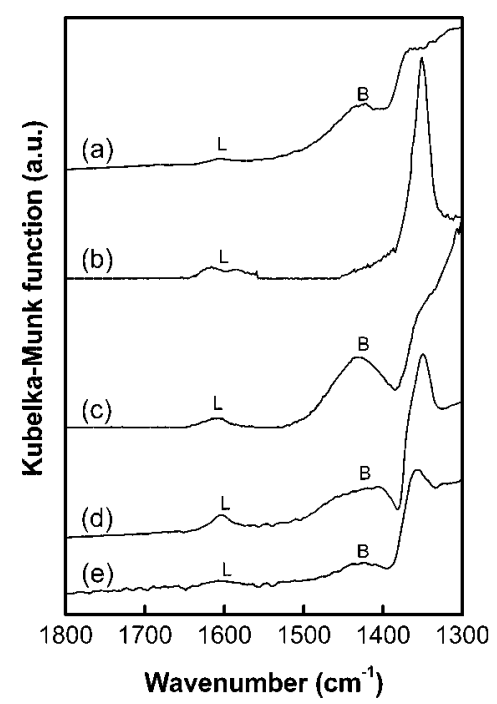

Figure 5. DRIFT spectra of the adsorption of $\mathrm{NH}_{3}$ at $120{ }^{\circ} \mathrm{C}$ on (a) $2 \mathrm{~A} / \mathrm{MP}-\mathrm{ZrO}_{2}$, (b) $2 \mathrm{~A} / \mathrm{MP}-\mathrm{ZrO}_{2}$ (uncalcined), (c) $2 \mathrm{AS} / \mathrm{MP}-\mathrm{ZrO}_{2}$, (d) $2 \mathrm{~S} /$ $\mathrm{MP}-\mathrm{ZrO}_{2}$, and (e) $\mathrm{MP}-\mathrm{ZrO}_{2}$ catalysts and followed by desorption at $250{ }^{\circ} \mathrm{C}$. (B = Brønsted acid sites; $\mathrm{L}=$ Lewis acid sites.)

aluminum sulfate. As shown in Figure 5, they behaved differently in the desorption of adsorbed $\mathrm{NH}_{3}$ at $250{ }^{\circ} \mathrm{C}$. In the case of $\mathrm{MP}-\mathrm{ZrO}_{2}$, even though the IR bands correspond to the Lewis and Brønsted acid sites appeared slightly at low temperatures (not shown here), they nearly vanished at a desorption temperature of $250{ }^{\circ} \mathrm{C}$. On the other hand, the IR bands due to $\mathrm{NH}_{3}$ adsorbed on both acid sites were still observed at this temperature for the samples $2 \mathrm{~S} / \mathrm{MP}-\mathrm{ZrO}_{2}$ and $2 \mathrm{AS} / \mathrm{MP}-\mathrm{ZrO}_{2}$. However, the band intensity corresponding to Brønsted acid sites for 2AS/ $\mathrm{MP}-\mathrm{ZrO}_{2}$ sample is quantitatively higher than that for nonpromoted SZ catalyst $2 \mathrm{~S} / \mathrm{MP}-\mathrm{ZrO}_{2}$.

One notes that the DRIFT spectrum of 2A/MP$\mathrm{ZrO}_{2}$ (uncalcined) is distinctively different from $2 \mathrm{~A} / \mathrm{MP}-\mathrm{ZrO}_{2}$ in that only IR bands due to $\mathrm{NH}_{3}$ adsorbed on the Lewis acid sites are observed (around $1609 \mathrm{~cm}^{-1}$ ). Therefore, we can 

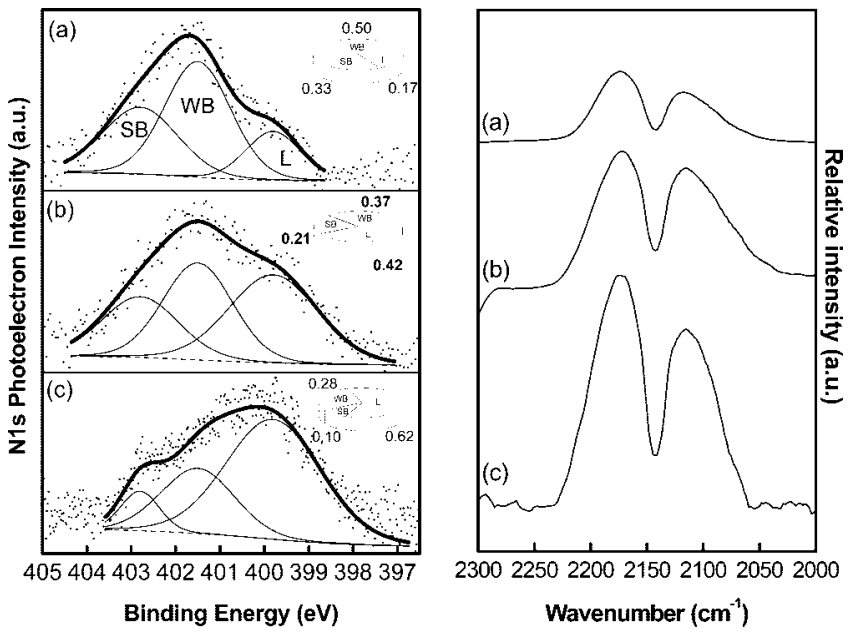

Figure 6. The N1s photoelectron profiles with pyridine (left) and IR spectra with $\mathrm{CO}$ (right) adsorbed on (a) $2 \mathrm{AS} / \mathrm{MP}-\mathrm{ZrO}_{2}$, (b) $1 \mathrm{AS} / \mathrm{MP}-$ $\mathrm{ZrO}_{2}$, and (c) $1 \mathrm{AS}+\mathrm{S} / \mathrm{MP}-\mathrm{ZrO}_{2}$ catalysts after activation.

conclude that the formation of Brønsted acid sites requires the participation of $\mathrm{Al}$ species with high calcination temperatures such as $630{ }^{\circ} \mathrm{C}$. Moreover, the strong sharp peak at $1355 \mathrm{~cm}^{-1}$ in $2 \mathrm{~A} / \mathrm{MP}-\mathrm{ZrO}_{2}$ (uncalcined) due to aluminum nitrate, or its hydrolyzed product formed during the impregnation process, disappeared after calcination at $630{ }^{\circ} \mathrm{C}$. Thus, the extraframework $\mathrm{Al}$ species substitute into the $\mathrm{MP}-\mathrm{ZrO}_{2}$ framework after the calcination process.

Although $\mathrm{NH}_{3}$ can be used as a probe (e.g., in DRIFT study) to differentiate between Brønsted and Lewis acid sites on a catalyst, it has a limitation in that no quantitative information could be derived on the distribution of Brønsted acid strength. To overcome this problem, we turned to XPS. Previously, we have measured XPS spectra of the $\mathrm{N}$ 1s peak of adsorbed pyridine to investigate the type and strength of acid sites displayed by SZ catalysts by resolving the spectra into three components of different type and strength of acid sites on catalysts. ${ }^{15}$ Three kinds of acid sites were identified on the catalyst: a Lewis site, a weak Brønsted site, and a strong Brønsted site. In Figure 6 (left), the XPS N 1s spectra of catalysts $2 \mathrm{AS} / \mathrm{MP}-\mathrm{ZrO}_{2}, 1 \mathrm{AS} / \mathrm{MP}-\mathrm{ZrO}_{2}$, and $1 \mathrm{AS}+\mathrm{S} / \mathrm{MP}-\mathrm{ZrO}_{2}$ were then fitted by three singlet peaks corresponding to the difference degree of interaction between pyridine and the acid sites. These catalysts were chosen for XPS study because of their special characteristic in catalysis (see Figure 2 and Table 1). The peak of lowest $\mathrm{BE}(399.8 \mathrm{eV})$ corresponds to the pyridine atom coordinated to the Lewis acid site. The peaks at medium and highest BEs (401.5 and $402.8 \mathrm{eV}$ ) would be due to the pyridinium ions on medium and strong strengths of Brønsted acid sites, respectively. The assignment of these peaks and their respective BEs are in accordance with our previous published work. ${ }^{15}$ Relative concentrations of the three kinds of acid sites for each catalyst were summarized in the pie charts (inserts of Figure 6, left). They are quite different for different loadings of Al. For probing the Lewis acid site, we used CO as a probe molecule as its FTIR spectra are measured. ${ }^{30}$ In fact, the DRIFT CO adsorption analysis also showed that Lewis acidity was present in SZ promoted by alumina. This is shown in Figure 6 (right) demonstrating that when probe molecule $\mathrm{CO}$ interacts with coordinatively unsaturated cations on surface, a band at $v_{\mathrm{co}} \approx 2200 \mathrm{~cm}^{-1}$ was observed. From literature data, ${ }^{31}$ this band is ascribed to $\mathrm{CO}$ molecules interacting with the surface $\mathrm{Zr}^{4+}$ cations that are responsible for Lewis acidity. In our case here, the fraction of Lewis acid sites is the highest in $1 \mathrm{AS}+\mathrm{S} / \mathrm{MP}-\mathrm{ZrO}_{2}$ (with the highest amount of surface density in $\mathrm{S}$ ) but moderate in $1 \mathrm{AS} / \mathrm{MP}-\mathrm{ZrO}_{2}$ and $2 \mathrm{AS} / \mathrm{MP}-\mathrm{ZrO}_{2}$, which are in close agreement with the pyridine adsorbed XPS results.

3.4. Redox Properties of Catalysts. Besides the structure and acidity described in sections 3.1 and 3.2 , attentions also focused on the redox properties for these catalysts. We have checked for paramagnetic sites on our catalysts by using EPR. In pure $\mathrm{MP}-\mathrm{ZrO}_{2}$ (Figure $7 \mathrm{a}$ ), $\mathrm{Zr}^{3+}$ and $\mathrm{O}_{2}{ }^{-}$paramagnetic sites are observed, and this finding is in line with the published EPR results of Jentoft et al. ${ }^{32} \mathrm{Zr}^{3+}$ is a coordinatively unsaturated site with an oxygen vacancy and $\mathrm{O}_{2}{ }^{-}$could be formed by the interaction between adsorbed $\mathrm{O}_{2}$ with the F-center electron. On the other hand, in $2 \mathrm{AS} / \mathrm{MP}-\mathrm{ZrO}_{2}$ catalyst (Figure $7 \mathrm{~d}$ ), the $\mathrm{Zr}^{3+}$ sites diminished in number, but much more new $\mathrm{O}_{2}{ }^{-}$species are now formed. A reasonable explanation for this phenomenon is that $\mathrm{Zr}^{3+}$ has been oxidized to the coordinatively saturated

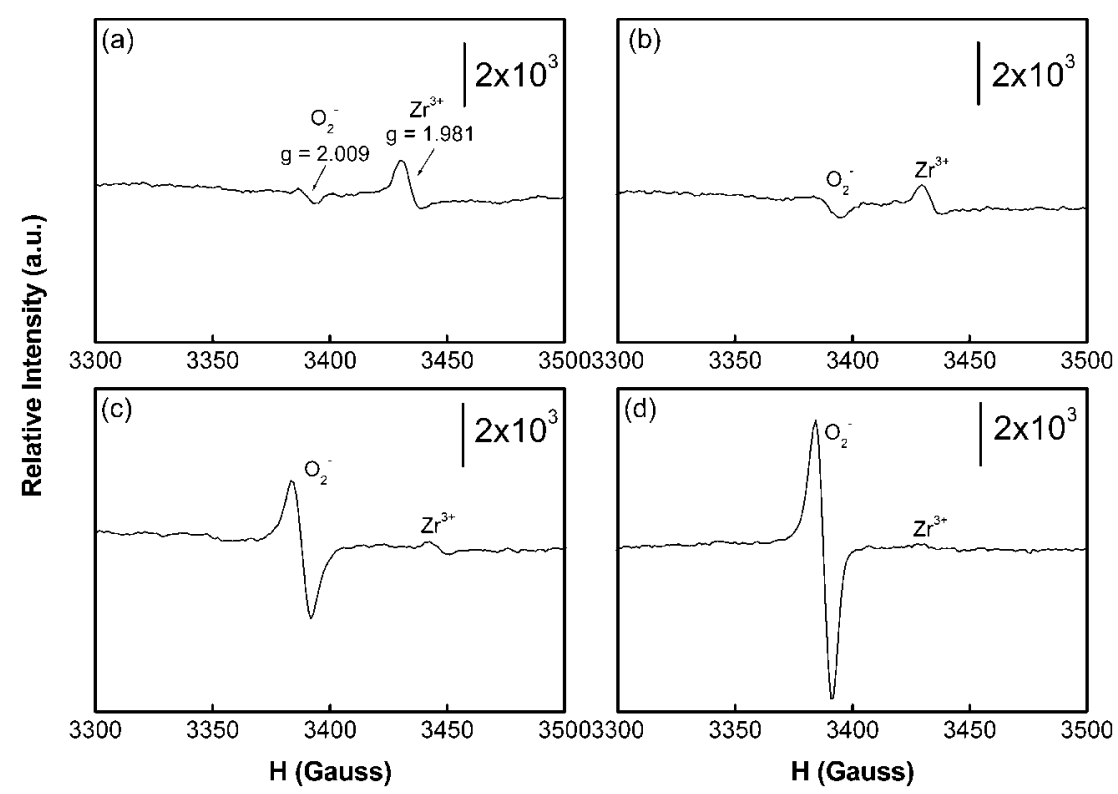

Figure 7. EPR spectra of (a) $\mathrm{MP}-\mathrm{ZrO}_{2}$, (b) $2 \mathrm{~A} / \mathrm{MP}-\mathrm{ZrO}_{2}$, (c) $9 \mathrm{~S} / \mathrm{MP}-\mathrm{ZrO}_{2}$, and (d) $2 \mathrm{AS} / \mathrm{MP}-\mathrm{ZrO}_{2}$ catalysts degassed at room temperature under vacuum and recorded at $-196{ }^{\circ} \mathrm{C}$. 

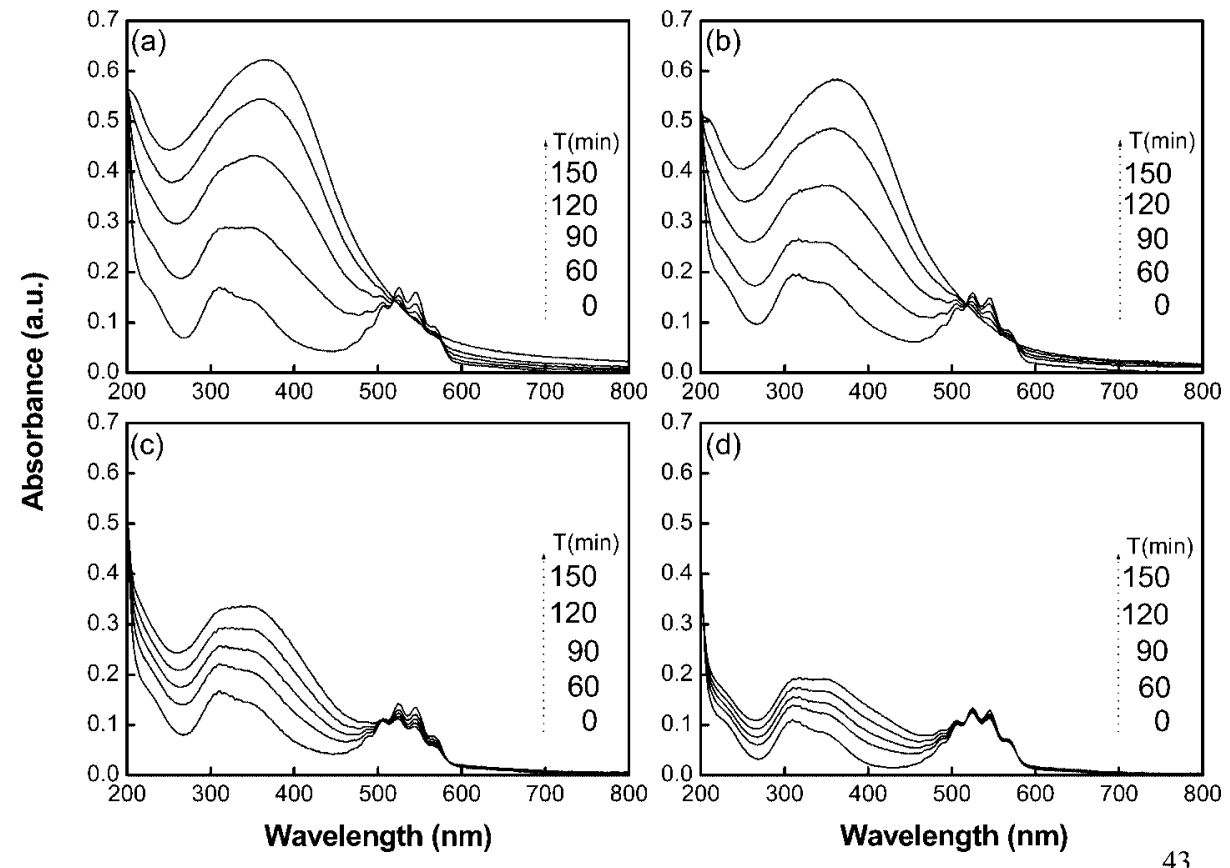

Figure 8. UV-vis spectra of $\mathrm{KMnO}_{4}$ aqueous solution used to check unsaturated olefin species produced by (a) $2 \mathrm{AS} / \mathrm{MP}-\mathrm{ZrO}{ }_{2}$, (b) $9 \mathrm{~S} / \mathrm{MP}-\mathrm{ZrO}{ }_{2}$, (c) $2 \mathrm{~A} / \mathrm{MP}-\mathrm{ZrO}_{2}$, and (d) $\mathrm{MP}-\mathrm{ZrO}_{2}$ samples during the $n$-butane isomerization.

$\mathrm{Zr}^{4+}$ state and the electron released is responsible for the formation of new $\mathrm{O}_{2}{ }^{-}$species. Very likely, surface adsorbed $\mathrm{SO}_{x}$ species are involved in this oxidation process whereby one of its oxygens is now filling the oxygen vacancy previously associated with $\mathrm{Zr}^{3+}$. Indeed, we found that the intensity of this new $\mathrm{O}_{2}{ }^{-}$signal correlates with the amount of sulfur in the catalyst. Superoxide species may be then correlated with the oxidative dehydrogenation ability of the catalyst. Li et al. have reported that butene species formed by oxidation of $n$-butane are shown to be the key intermediate during $n$-butane isomerization on SZ catalysts. ${ }^{17}$ Therefore, we adopted the Baeyer test - a conventional method to check the oxidation of alkenes with aqueous potassium permanganate $\left(\mathrm{KMnO}_{4}\right)$ - to explore whether certain unsaturated olefin species were formed oxidatively by our catalysts in the initiating step of butane isomerization. Since $\mathrm{MnO}_{4}{ }^{-}$is purple and $\mathrm{MnO}_{2}$ is light brown, this color change can be used to assay for the presence of alkenes. Figure 8 illustrates the corresponding time-dependent UV-vis spectra of $\mathrm{KMnO}_{4}$ aqueous solution at room temperature. Potassium permanganate is a powerful oxidant, and we can attribute the formation of $\mathrm{MnO}_{2}$ to the direct redox between olefin species and $\mathrm{KMnO}_{4}$ because there were no other reducing products. With the elapsed reaction time, it can be easily seen that three peaks at about 315,525 , and $545 \mathrm{~nm}$, which originated from $\mathrm{KMnO}_{4}$ gradually disappeared with the concurrence of a new peak shifted to $370 \mathrm{~nm}$ which indicated the formation of $\mathrm{MnO}_{2}$ aqueous solution.

One can note that the spectra corresponding to $\mathrm{KMnO}_{4}$ reduction to $\mathrm{MnO}_{2}$ by the species generated from $2 \mathrm{AS} / \mathrm{MP}-\mathrm{ZrO}_{2}$ catalyst (Figure 8a) change much more apparently than those from the other catalysts at the same time interval shown in parts $\mathrm{b}-\mathrm{d}$ of Figure 8. It implies that the higher radical concentration the catalyst, such as $2 \mathrm{AS} / \mathrm{MP}-\mathrm{ZrO}_{2}$, the stronger ability it oxidizes $n$-butane to the olefin species such as butene. On the other hand, it is noteworthy of mentioning again that the EPR signal to radical correlates directly with the amount of sulfur in the catalyst.

To explore the active sites on $2 \mathrm{AS} / \mathrm{MP}-\mathrm{ZrO}_{2}$ surface interacting with butane molecules during isomerization, in situ diffuse-

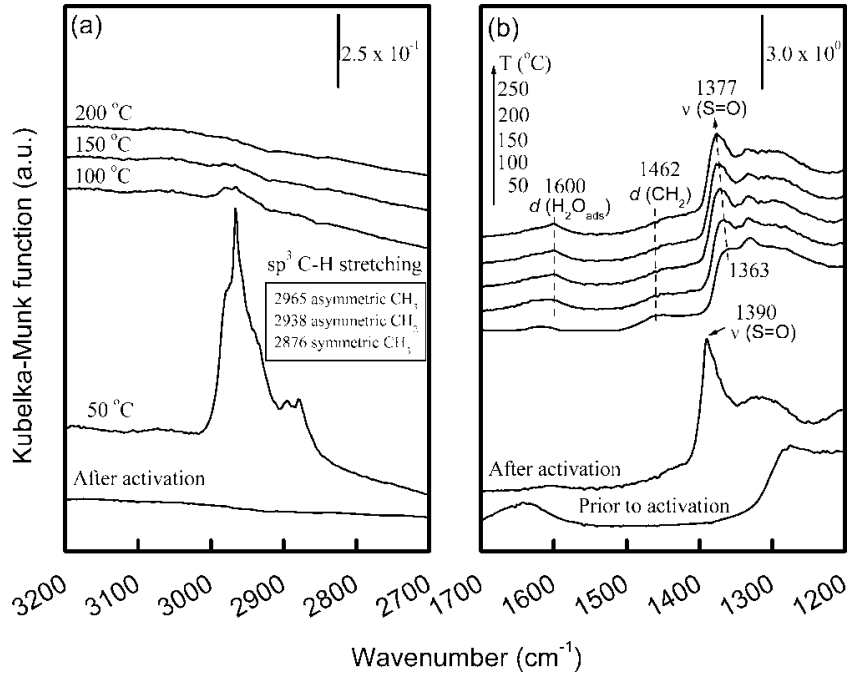

Figure 9. In situ DRIFT spectra of $2 \mathrm{AS} / \mathrm{MP}-\mathrm{ZrO}_{2}$ catalyst recorded before and after activation and followed by desorption at the range from 100 to $250{ }^{\circ} \mathrm{C}$ after the adsorption of n-butane at $50{ }^{\circ} \mathrm{C}$ on the activated catalyst.

reflectance IR was collected to monitor the gas-solid interaction between them. The $2 \mathrm{AS} / \mathrm{MP}-\mathrm{ZrO}_{2}$ sample was first activated at $400{ }^{\circ} \mathrm{C}$ for $30 \mathrm{~min}$ in an air flow, and then the adsorption of butane was done by flowing butane $(\geq 99.9 \%)$ through the activated sample at $50{ }^{\circ} \mathrm{C}$ for $5 \mathrm{~min}$. Finally the system was flushed with dry air for $10 \mathrm{~min}$.

Figure 9 illustrates the IR spectrum of the calcined but not yet activated catalyst is typical of hydrated surface with adsorbed water (1600-1700 $\mathrm{cm}^{-1}$ range). Activation in a flowing dry air results in strong reduction of this broadband, and the spectrum of the activated sample exhibits an distinctive band at $1390 \mathrm{~cm}^{-1}$ (Figure 9b), which is assigned to the stretching vibration of the $\mathrm{S}=\mathrm{O}$ bond in adsorbed $\mathrm{SO}_{3}$ molecules. ${ }^{28}$ The band at $2850-3010 \mathrm{~cm}^{-1}$ (Figure 9a) and a small shoulder at about $1462 \mathrm{~cm}^{-1}$ (Figure 9b) correspond to butane adsorbates on the $2 \mathrm{AS} / \mathrm{MP}-\mathrm{ZrO}_{2}$ surface. In the initial process of desorption, 
even though the IR bands correspond to the butane molecules appeared strongly at low temperatures due to physisorption, they nearly vanished above a desorption temperature of $150{ }^{\circ} \mathrm{C}$. Another interesting feature is that $2 \mathrm{AS} / \mathrm{MP}-\mathrm{ZrO}_{2}$ catalyst with its stretching vibration of the $\mathrm{S}=\mathrm{O}$ bond located at $1390 \mathrm{~cm}^{-1}$ shifted downward to $1363 \mathrm{~cm}^{-1}$ when exposed to butane molecules. As the desorption temperature increased the vibration band shifted upward in the range of $1363-1377 \mathrm{~cm}^{-1}$. This phenomenon hints that there are certain kinds of interaction between butane molecules and the active sites on $2 \mathrm{AS} / \mathrm{MP}-\mathrm{ZrO}_{2}$ catalyst during the isomerization reaction. In other words, it is reasonable for us to visualize that species adsorbed on AS/MP$\mathrm{ZrO}_{2}$ catalyst, a labile $\mathrm{SO}_{3}$ surface species, are likely to be the active sites involving the butane isomerization reaction. The formation of water during desorption process is shown by the increasing intensity of the deformation band at $1600 \mathrm{~cm}^{-1}$ (Figure 9b) with desorption of the butane molecules (Figure $9 \mathrm{a})$. The gradual formation of water on $2 \mathrm{AS} / \mathrm{MP}-\mathrm{ZrO}_{2}$ catalyst also indicates the butane molecules were activated via oxidative dehydrogenation to form butane and water by the $\mathrm{SO}_{3}$ groups.

\section{Discussion}

Since the discovery of the strong acidic property of SZ, a great deal of work have been reported on their application in $n$-alkane isomerization reaction. However, there is a diversity of opinions on the mechanism and reactive centers of alkane isomerization reaction over SZ, which is further complicated by that the reactions were carried out under a vast number of conditions and catalyst modifications. In this paper, we set our goal to clarify the role of alumina promotion (active site and reaction pathway) in the two main functions of SZ in the $n$-butane isomerization reaction, that is, its redox activation of $n$-butane to butene and the role of acidity in isomerization..

4.1. General Comment on Catalytic Performance. In this study, the main group metal Al was successfully incorporated into $\mathrm{S} / \mathrm{MP}-\mathrm{ZrO}_{2}$ and enhanced substantially the catalytic activity and stability of $n$-butane isomerization reaction. By comparison of catalysts with and without $\mathrm{Al}$, Table 1 shows that alumina is highly promoting in catalytic activity. From the sulfur content in Table 1, one can see that $\mathrm{Al}$ increases the sulfur loading by at least 10 -folds. However, the more than 100-fold increase in activity need consideration other than sulfur loading. Previously, Gao and co-workers reported a 2.2-fold increase in catalytic activity in $\mathrm{Al}$ promotion of SZ. ${ }^{33}$ Here, the promotional effect of $\mathrm{Al}$ to $\mathrm{S} / \mathrm{MP}-\mathrm{ZrO}_{2}$ is even more striking. Anyway, the loading of alumina and then increased sulfates groups has four consequences in (1) stabilizing the active tetragonal crystalline phase of zirconia, (2) increasing total surface area, (3) enhancing the Brønsted acidity, and (4) increasing the oxidative dehydrogenation. In our previous report, we have discussed the enhanced stability of tetragonal phase (the more active phase) of zirconia upon promotion of $\mathrm{Al}^{8}{ }^{8}$ Also, from Table 1 we do see there is an increase in total surface area of $\mathrm{MP}-\mathrm{ZrO}_{2}$, similar to the observation of Kim et al. ${ }^{34}$ However, the increased surface area cannot account for the very large increase in catalytic activity. It can only be a minor factor. Thus in this work, we focus on the last two effects of $\mathrm{Al}$ on the acidity and redox properties of SZ.

Our discussions will be based on both structural characterizations of the catalyst and the reaction mechanism of butane isomerization. Thus before presenting our discussions, we would like to give summary of the reaction mechanism that will fit nicely with our data. There are two reaction models commonly used to describe the $n$-alkane isomerization reaction over SZ solid acids, namely, the monomolecular model and the bimolecular model. There is still controversy over the operation of the two mechanisms in butane isomerization on SZ. ${ }^{35-39}$ In monomolecular mechanism, ${ }^{35,36}$ the formation of a protonated cyclopropane ring from $\mathrm{C}_{4}{ }^{+}$carbenium ion on $\mathrm{SZ}$ is the crucial step. The monomolecular mechanism can satisfactorily explain the high selectivity for isobutene, especially at initial time-onstream. On the other hand, the bimolecular mechanism occurs through the formation of $\mathrm{C}_{8}{ }^{+}$carbenium ion, which is resulted from reacting $\mathrm{C}_{4}{ }^{+}$with butane. ${ }^{37-39}$ The $\mathrm{C}_{8}{ }^{+}$species then undergoes isomerization and $\beta$-scission. The bimolecular mechanism is supported for its lower activation energy, isotope scrambling, ${ }^{37,39}$ and the $\mathrm{C}_{3}$ and $\mathrm{C}_{5}$ disproportion products. ${ }^{40}$ Recently, after studying the nonspecific olefin promotional effect, Goodwin and co-workers ${ }^{41}$ proposed a dual-nature mechanism that integrates the supporting evidence for the above two mechanisms. In the dual-nature model, the $\mathrm{C}_{8}{ }^{+}$species is formed but the part from the $\mathrm{C}_{4}^{+}$acts "as though" in a monomolecular isomerization. The reaction pathway is summarized in Scheme 1, after small modifications. In Scheme 1, one can see in the major route, the isomerization along the circled part is really monomolecular in nature although it is attached to an butane (olefin)-derived $\mathrm{C}_{4}$ and become part of a $\mathrm{C}_{8}{ }^{+}$species. Disproportional scission only occurs occasionally.

The product distribution is related to the reaction pathway taken; the catalytic performances over the three selected samples of various $\mathrm{Al}$ and $\mathrm{S}$ loadings, as summarized in Table 2, are quite different in conversion and selectivity. A high selectivity for isobutane implies a dominant pseudomonomolecular mechanism as indicated by the circles in Scheme 1. In the initial period, the conversions are higher and the selectivities lower. Furthermore, the production of propane is a lot more than pentane. This could be due to the activity of strong Brønsted acid in forming oligomer species of higher carbon number $\left(\mathrm{C}_{12}\right.$ and beyond) and its cracking leading to the volatile propane and the less desorbing higher alkane species stay on the surface of SZ to form coking species. The cokes eliminate some of the strong Brønsted acid site and decrease to a steady activity. The steady state is probably dominated by the pseudo-monomolecular mechanism in Scheme 1 , and the side products $C_{3}$ and $\mathrm{C}_{5}$ are found to be in equal amount. After $60 \mathrm{~min}$, the activity stabilized gradually and selectivity maintained a stable value above $90 \%$. This implies long chain reaction propagation length, probably more than 500 skeleton isomerization of secbutyl carbenium for each oxidation step. ${ }^{42} \mathrm{We}$ note that $\mathrm{Al}-$ promoted catalysts show only minor decay of activity from initial to steady activity compared to most other reports in literature. Al not only promoted but the catalytic activity but also make it more steady. From Table 1, one can see that increasing the sulfur content without also increasing $\mathrm{Al}$ content would increase the initial activity but it would quickly decay. This may be due to the relatively weak acidity, which leads to less coking and the easy transport in mesostructure of aluminapromoted S/MP- $\mathrm{ZrO}_{2}$. This decreases the need of coke elimination processes, such as repeated calcinations, supercritical fluid processing, ${ }^{43,44}$ or using the expensive platinum. ${ }^{45}$ In our catalytic process, $\mathrm{Pt}$ is not needed to prevent coke formation at all because little coking exists under the action of relatively mild acid sites.

4.2. Strong Brønsted (SB), Weak Brønsted (WB), and Lewis (L) Acid Sites. In our previous study of the acidity of Al-promoted SZ, ${ }^{14}$ we have identified by XPS measurement of adsorbed pyridine three kinds of acid sites: one Lewis acid (L), one strong Brønsted (SB), and one weak Brønsted (WB) site. We reported the catalytic activity for butane isomerization is 


\section{SCHEME 1: Mechanism for $\boldsymbol{n}$-Butane Isomerization}

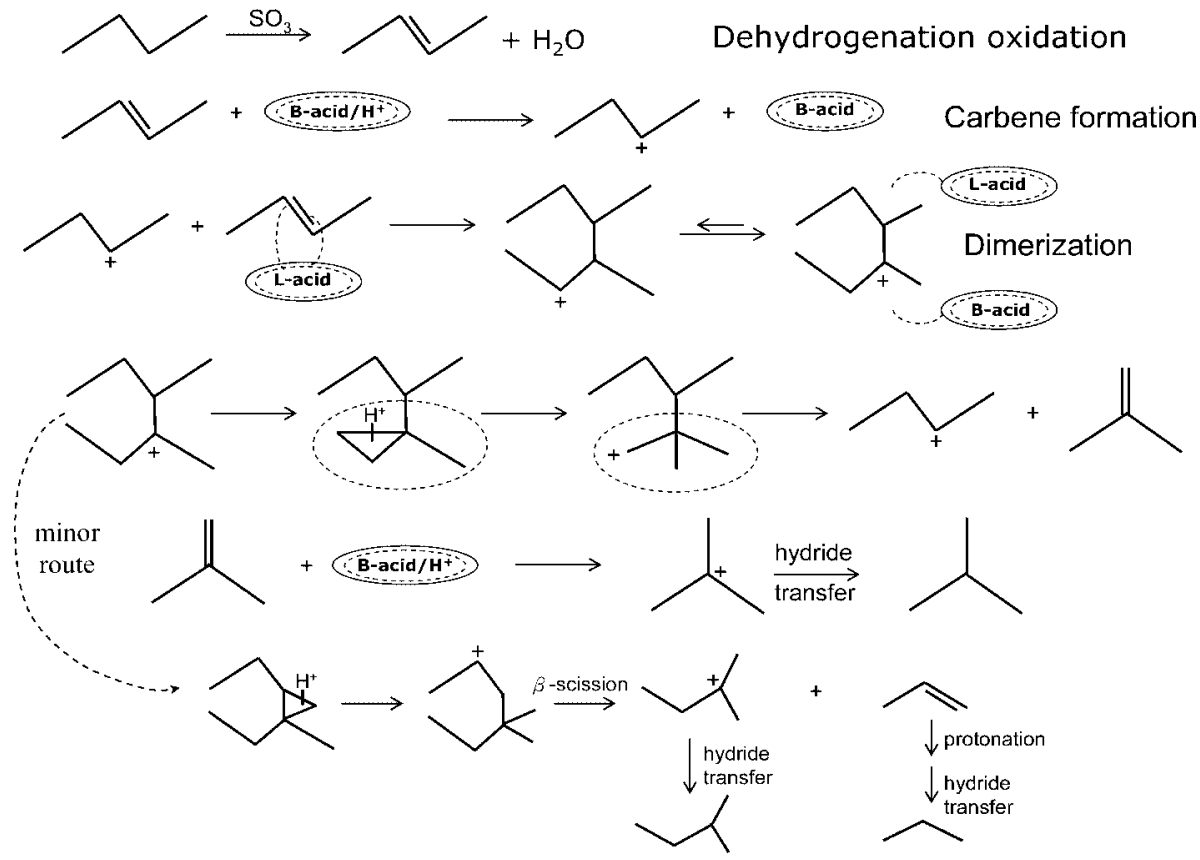

TABLE 2: Catalytic Conversion, Selectivity, and Yield in $n$-Butane Isomerization at $250{ }^{\circ} \mathrm{C}$ after $15 \mathrm{~min}, 50 \mathrm{~min}$, and at Steady State Regime over the 3 Selected Samples

\begin{tabular}{|c|c|c|c|c|c|c|}
\hline \multirow[b]{2}{*}{ catalyst $^{a}$} & \multirow{2}{*}{$\begin{array}{c}\text { conversion } \\
(\%)\end{array}$} & \multirow{2}{*}{$\begin{array}{c}\text { selectivity } \\
(\%)\end{array}$} & \multicolumn{4}{|c|}{ yield $(\%)$} \\
\hline & & & $\mathrm{C}_{2}$ & $\mathrm{C}_{3}$ & $i-\mathrm{C}_{4}$ & $i-\mathrm{C}_{5}$ \\
\hline \multicolumn{7}{|c|}{ After $15 \mathrm{~min}$} \\
\hline $2 \mathrm{AS}$ & 58.63 & 85.1 & 1.55 & 5.87 & 49.92 & 1.29 \\
\hline $1 \mathrm{AS}$ & 34.22 & 93.0 & 0.30 & 1.15 & 31.83 & 0.94 \\
\hline $1 \mathrm{AS}+\mathrm{S}$ & 43.98 & 87.0 & 0.37 & 3.99 & 38.28 & 1.34 \\
\hline \multicolumn{7}{|c|}{ After $50 \mathrm{~min}$} \\
\hline $2 \mathrm{AS}$ & 52.67 & 92.1 & 1.05 & 1.62 & 48.53 & 1.47 \\
\hline $1 \mathrm{AS}$ & 34.15 & 93.5 & 0.28 & 0.97 & 31.94 & 0.96 \\
\hline $1 \mathrm{AS}+\mathrm{S}$ & 35.64 & 89.5 & 0.22 & 2.13 & 31.88 & 1.41 \\
\hline \multicolumn{7}{|c|}{ After $360 \mathrm{~min}$} \\
\hline $2 \mathrm{AS}$ & 46.91 & 92.1 & 0.80 & 1.47 & 43.20 & 1.44 \\
\hline $1 \mathrm{AS}$ & 26.03 & 95.6 & 0.19 & 0.48 & 24.89 & 0.47 \\
\hline $1 \mathrm{AS}+\mathrm{S}$ & 11.79 & 96.7 & 0.07 & 0.17 & 11.40 & 0.15 \\
\hline
\end{tabular}

${ }^{a}$ Catalysts used mesoporous zirconia ( $\left.\mathrm{MP}-\mathrm{ZrO}_{2}\right)$ as support.

closely correlated to the concentration of WB sites. But high catalytic performance was also attributed to the simultaneous presence of Brønsted and Lewis acid sites. ${ }^{22}$ Our results from ${ }^{27} \mathrm{Al}$ MAS NMR (Figure 4) and $\mathrm{NH}_{3}$ DRIFT (Figure 5) studies on $2 \mathrm{AS} / \mathrm{MP}-\mathrm{ZrO}_{2}$ catalyst suggest that $\mathrm{Br} \varnothing n$ sted acid sites are created by the isomorphous substitution of $\mathrm{Zr}^{4+}$ by $\mathrm{Al}^{3+}$. However, $\mathrm{Al}^{3+}$ substitution may be only minor since it did not cause a significant change in the coordination environment of $\mathrm{Zr}^{4+}$ in the catalyst judging from the absence of a peak broadening effect in our EXAFS spectrum (not shown). In other words, $\mathrm{Al}^{3+}$ probably occupied only the surface $\mathrm{Zr}^{4+}$ sites. Hua et al. have used XPS to study the composition of aluminapromoted $\mathrm{SZ}$ and also found that the atomic ratio of $\mathrm{Al} / \mathrm{Zr}$ at the surface is much higher than that in the bulk. ${ }^{33}$ Anyway, the concentration of Brønsted acid sites depends directly on the amount of substituted $\mathrm{Al}$ in the surface layer of the catalyst.

According to our pyridine XPS results (Figure 6, left), Brønsted acid sites can be divided into two groups of different acid strength. To be a good catalyst, the concentration of SB and WB (or even the L) sites need to be balanced, and they complement each other during different stages of reaction as we shall explain below. Generally, the stronger the Brønsted acid sites, the faster the rate of $\mathrm{C}_{4} \mathrm{H}_{9}{ }^{+}, \mathrm{C}_{8} \mathrm{H}_{17}{ }^{+}$, and isobutane formation. However, the rate of deactivation by coke formation is also faster. Obviously, a larger number of SB sites will promote the initial rate of reaction. However, this will also promote coke formation. In order to sustain the reaction through the later stages of reaction, there must be many WB sites which are less susceptible to deactivation by coke formation. Undoubtedly, WB sites played an important role in the steady stages of reaction. ${ }^{33}$

The origin of $\mathrm{L}$ sites which have a weaker acid strength is not all clear. On the one hand, our $\mathrm{NH}_{3}$ DRIFT study (Figure 5) showed that one of the candidates is the extra-framework $\mathrm{Al}$ species. On the other hand, our pyridine XPS study cannot exclude the possible involvement of surface $\mathrm{Zr}$ species with oxygen deficiency next to it in the formation of $\mathrm{L}$ sites (compare $1 \mathrm{AS} / \mathrm{MP}-\mathrm{ZrO}_{2}$ and $1 \mathrm{AS}+\mathrm{S} / \mathrm{MP}-\mathrm{ZrO}_{2}$ in Figure 6). As shown in Scheme 1, we propose that the olefin species is adsorbed on a $\mathrm{L}$ acid site (olefin modified acid site), while a neighboring Brønsted acid site with an adsorbed carbenium ion would promote the formation of the dimer $\mathrm{C}_{8}{ }^{+}$species. This explains the necessity of simultaneous presence of $\mathrm{L}$ and $\mathrm{B}$ sites.

4.3. Dehydrogenation of $\boldsymbol{n}$-Butane. In all the mechanisms proposed so far, an initial formation of butene species is necessary for the carbenium formation upon reacting with a Brønsted acid site. In the unpromoted or non transition metalpromoted SZ catalysts, the nature of dehydrogenation site(s) for $n$-alkane is not known for certain. As these catalysts do not possess superacidity, dehydrogenation of $n$-butane by a protonation barbonium mechanism does not seem to be a feasible proposal. There must be some other site(s) on the SZ catalyst capable of performing the dehydrogenation. Recently, oxidative dehydrogenation has been proposed as a possible route for butene formation since sulfate group does have strong oxidative power. ${ }^{17,18}$

From the Bayer test (Figure 8), we have substantial production of butene catalyzed by the catalyst with the dehydrogenation process. The in situ DRIFT vibrational spectra in Figure 9 
identify that butane interact with the sulfate group on the surface of the 2AS/MP- $\mathrm{ZrO}_{2}$ catalyst. FÖttinger et al. ${ }^{28}$ assigned pyrosulfate species to a vibrational wavenumber above 1400 $\mathrm{cm}^{-1}$ while $(\mathrm{ZrO})_{3} \mathrm{~S}=\mathrm{O}\left(\mathrm{SO}_{3}\right.$ species $)$ would give peak slightly below $1400 \mathrm{~cm}^{-1}$. Since our DRIFT spectra gives a peak at $1390 \mathrm{~cm}^{-1}$, we believe we have mainly dispersed $\mathrm{SO}_{3}$ species on the surface. Apparently, this $\mathrm{SO}_{3}$ species reacts with butane to give butene which is the starting species for the rest of acidcatalyzed isomerization reactions ${ }^{42}$

$$
\mathrm{C}_{4} \mathrm{H}_{10}+\mathrm{SO}_{3} \rightarrow \mathrm{C}_{4} \mathrm{H}_{8}+\mathrm{H}_{2} \mathrm{O}+\mathrm{SO}_{2}
$$

It is quite possible the oxidative dehydrogenation would also involve some radical species to induce hydrogen transfer from butane. We then set out to look for radical species on our 2AS/ $\mathrm{MP}-\mathrm{ZrO}_{2}$ catalyst. In pure $\mathrm{MP}-\mathrm{ZrO}_{2}, \mathrm{Zr}^{3+}$ and $\mathrm{O}_{2}{ }^{-}$paramagnetic sites are observed, and this finding is inline with the published EPR results of Jentoft and co-workers. ${ }^{32} \mathrm{Zr}^{3+}$ is a coordinatively unsaturated site with an oxygen vacancy, and $\mathrm{O}_{2}{ }^{-}$may be formed by the interaction between adsorbed $\mathrm{O}_{2}$ with the F-center electron. Upon the loading of $\mathrm{Al}$ and $\mathrm{S}$, in $2 \mathrm{AS} / \mathrm{MP}-\mathrm{ZrO}_{2}$ catalyst the $\mathrm{Zr}^{3+}$ sites diminished in number but much more new $\mathrm{O}_{2}{ }^{-}$species are now formed. Surely, a reasonable explanation for this phenomenon is that $\mathrm{Zr}^{3+}$ has been oxidized to the coordinatively saturated $\mathrm{Zr}^{4+}$ state and the electron released is responsible for the formation of new $\mathrm{O}_{2}{ }^{-}$species. Very likely, surface adsorbed $\mathrm{SO}_{3}$ species (Figure 9) are involved in this oxidation process, whereby one of its oxygen atoms is now filling the oxygen vacancy previously associated with $\mathrm{Zr}^{3+}$. Indeed, we found that the intensity of this new $\mathrm{O}_{2}^{-}$signal correlates directly to the amount of $\mathrm{S}$ in the catalyst. It is tempting for us to assign the $\mathrm{O}_{2}{ }^{-}$species (or its derivatives formed under reaction conditions) as a possible oxidative agent. In that case, the concentration of dehydrogenation sites should also correlate directly to the $\mathrm{S}$ content of a catalyst which indeed we found in comparing parts $\mathrm{c}$ and $\mathrm{d}$ of Figure 7. Furthermore, one of the roles played by $\mathrm{Al}$ is to chemisorb more $\mathrm{SO}_{3}$ species on the surface during the catalyst preparation process as we have mentioned in section 3.2. Indirectly, $\mathrm{Al}$ could also increase the concentration of dehydrogenation sites. Therefore, another of the promotional effects of $\mathrm{Al}$ (although acted indirectly) is to increase the number of dehydrogenation sites which is very important for the isomerization reaction to initiate. We also note that Lewis acid sites may play some role in the oxidative dehydrogenation. Lewis acid is known to promote oxidation reaction by coordinating with an oxygen species and enhancing the electrophilicity of these oxidizing reagents toward their reaction with weakly nucleophilic substrates. In any case, the concentration of $\mathrm{L}$ sites need not be large in the catalytic reaction.

In addition to the formation of butene by the initial oxidative dehydrogenation of butane, there may be more olefinic $\mathrm{CH}_{x}$ formed during the reaction (Scheme 1). This would lead to more active surface "olefin" species during the reaction and may play a secondary (or substitutional) role for $n$-butane activation. Goodwin and co-workers have shown that these olefinic species can increase the rate of butane isomerization reaction. ${ }^{46}$ Hence, the pristine dehydrogenation sites and the $\mathrm{CH}_{x}$ species will both ensure a continuous supply of olefins for the isomerization reaction.

\section{Conclusions}

In conclusion, we have investigated the promotional effect of alumina to mesoporous SZ on the butane isomerization. The doping of alumina to SZ increases the extent of sulfur retention on the surface of zirconia which then promotes the oxidative dehydrogenation to butane and the skeleton isomerization. A good catalyst of Al-SZ thus requires delicate balances of several steps in the reaction chain. Our design for an excellent lowtemperature active catalysts for alkane isomerization was benefited from (1) matching rate of isomerization of carbenium species with respect to the oxidative dehydrogenation capability and (2) balanced distribution of Brønsted acid and Lewis acid sites. A good performing catalyst with high initial activity requires high oxidative dehydrogenation rate. However, if it is not matched with enough weak Brønsted (WB) acid sites and Lewis (L) acid sites, the overproduced olefinic species would lead to coking and a decay of catalytic activity. For good steadystate activities, one then should have a balanced distribution of $\mathrm{SB}, \mathrm{WB}$, and $\mathrm{L}$ sites. We found that the optimum relative concentration of SB:WB:L sites is around 0.33:0.50:0.17 for our best performing $2 \mathrm{AS} / \mathrm{MP}-\mathrm{ZrO}_{2}$ catalyst. A substantial deviation from this optimum distribution of acid sites can have a delirious effect on the catalytic performance.

Possessing multifunctional catalytic capabilities, oxidation and acid-base, SZ catalysts may be further applied to other reactions, ${ }^{47}$ such as in esterification reaction for biodiesel production $^{3}$ or as a support for metal catalysts. ${ }^{48} \mathrm{We}$ have found in this work that doping SZ with alumina can fine-tune its catalytic properties. This will make our ability to design zirconiabased catalyst system better.

Acknowledgment. This work was supported by a grant from the National Science Council of Taiwan. We would like to thank technical helps from Dr. J.H. Wang and S.T. Wong.

\section{References and Notes}

(1) Hino, M.; Kobayashi, S.; Arata, K. J. Am. Chem. Soc. 1979, 101, 6439.

(2) Hino, M.; Arata, K. J. Chem. Soc. Chem. Commun. 1980, 851.

(3) Chen, X. R.; Ju, Y. H.; Mou, C. Y. J Phys. Chem. C 2008, 111, 18731 .

(4) Wan, K. T.; Khouw, C. B.; Davis, M. E. J. Catal. 1996, 158, 311.

(5) Hino, M; Arata, K. Catal. Lett. 1995, 30, 25. 101 .

(6) Gao, Z.; Xia, Y. D.; Hua, W. M.; Miao, C. X. Top. Catal. 1998, 6,

(7) Wang, W; Chen, C. L.; Xu, N. P.; Mou, C. Y. Green Chem. 2002, 4, 257.

(8) Chen, C. L.; Cheng, S.; Lin, H. P.; Wong, S. T.; Mou, C. Y. Appl. Catal., A 2001, 215, 21. 45 .

(9) Wang, J. H.; Mou, C. Y. Abstr. Pap. Am. Chem. Soc. 2002, 224,

(10) Chen, C. L.; Li, T.; Cheng, S. F.; Xu, N.; Mou, C. Y. Catal. Lett. 2002, 78, 223.

(11) Cao, C. J.; Han, S.; Chen, C. L.; Xu, N. P.; Mou, C. Y. Catal. Commun. 2003, 4, 511.

(12) Cao, C. J.; Yu, X. Z.; Chen, C. L.; Mou, C. Y. React. Kinet. Catal. Lett. 2004, 83, 85 .

(13) Wang, W.; Wang, J. H.; Chen, C. L.; Xu, N. P.; Mou, C. Y. Catal. Today 2004, 97, 307.

(14) Wang, J. H.; Mou, C. Y. Appl. Catal., A 2005, 286, 128.

(15) Wang, J. H.; Mou, C. Y. Microporous Mesoporous Mater. 2008, $110,260$.

(16) Wang, J. H.; Mou, C. Y. Catal. Today 2008, 131, 162.

(17) Li, X.; Nagaoka, K.; Simon, L. J.; Olindo, R.; Lercher, J. A.; Hofmann, A.; Sauer, J. J. Am. Chem. Soc. 2005, 127, 16159.

(18) Li, X.; Nagaoka, K.; Simon, L. J.; Lercher, J. A.; Wrabetz, S.; Jentoft, F. C.; Breitkopf, C.; Matysik, S.; Papp, H. J. Catal. 2005, 230, 214.

(19) Ciesla, U.; Fröba, M.; Stucky, G.; Schüth, F. Chem. Mater. 1999, $11,227$.

(20) Yang, X; Jentoft, R. E.; Jentoft, F. C.; Girgsdies, F.; Ressler, T. Catal. Lett. 2002, 81, 25.

(21) Sun, Y.; Yuan, L.; Ma, S.; Hua, Y.; Zhao, L.; Wang, W.; Chen, C. L.; Xiao, F. S. Appl. Catal., A 2004, 268, 17.

(22) Hammache, S.; Goodwin, J.G. J. Catal. 2003, 218, 258.

(23) Guisnet, M. R. Acc. Chem. Res. 1990, 23, 392.

(24) Sparks, D. E.; Keogh, R. A.; Davis, B. H. Appl. Catal., A 1996, $144,205$. 
(25) Niwa, M.; Habuta, Y.; Okumura, K.; Katada, N. Catal. Today 2003, 87, 213.

(26) Katada, K.; Tsubaki, T.; Niwa, M. Appl. Catal., A 2008, 340, 76.

(27) Baertsch, C. D.; Soled, S. L.; Iglesia, E. J. Phys. Chem. B 2001, 105,1320

(28) FÖttinger, K.; Halwax, E.; Vinek, H. Appl. Catal., A 2006, 301, 115.

(29) Bradley, S. M.; Howe, R. F.; Kydd, R. A. Magn. Reson. Chem. 1993, 31, 883.

(30) Breitkof, C.; Papp, H.; Li, X.; Olindo, R.; Lercher, J. A.; Lloyd, R.; Wrabetz, S.; Jentoft, F. C.; Meinel, K.; Foster, S.; Schindler, K.-M.; Neddermeyer, H.; Widdra, W.; Hofman, A.; Sauer, J. Phys. Chem. Chem. Phys. 2007, 9, 3600.

(31) Stichert, W.; Schüth, F.; Kuba, S.; Knözinger, H. J. Catal. 2001, 198, 277.

(32) Jentoft, F. C.; Hahn, A.; Kröhnert, J.; Lorenz, G.; Jentoft, R. E.; Ressler, T.; Wild, U.; Schlögl, R.; Hä $\beta$ ner, C.; Köhler, C. J. Catal. 2004, $224,124$.

(33) Hua, W.; Xia, Y.; Yue, Y.; Gao, Z. J. Catal. 2000, 196, 104.

(34) Kim, S. Y.; Lohitharn, N.; Goodwin, J. G.; Olindo, R.; Pinna, F.; Canton, P. Catal Commun. 2006, 7, 209.

(35) Tomishige, K.; Okabe, A.; Fujimoto, K. Appl. Catal., A 2000, 194, 383.
(36) Chao, K. J.; Wu, H. C.; Leu, L. J. J. Catal. 1995, 157, 289.

(37) Liu, H.; Adeeva, V.; Lei, G. D.; Sachtler, W. M. H. J. Mol. Catal. A: Chem. 1995, 100, 35.

(38) Kim, S. Y.; Goodwin, J. G., Jr.; Hammache, S.; Auroux, A.; Galloway, D. J. Catal. 2001, 201, 1.

(39) Adeeva, V.; Lei, G. D.; Sachtler, W. M. H. Appl. Catal., A 1994, 118, L11.

(40) Lohitharn, N; Goodwin, J. G.; Lotero, E. J. Catal. 2005, 234, 199.

(41) Lohitharn, N; Lotero, E; Goodwin, J. G. J. Catal. 2006, 241, 328.

(42) Li, X.; Nagaoka, K.; Simon, L. J.; Olindo, R.; Lercher, J. A. J. Catal. 2005, 232, 456

(43) Funamoto, T.; Nakagawa, T.; Segawa, K. Appl. Catal., A 2005, 286, 79 .

(44) Bogdan, V. I.; Klimenko, T. A.; Kustov, L. M.; Kazansky, V. B. Appl. Catal., A 2004, 267, 175.

(45) Demirci, U. B.; Garin, F. J. Mol. Catal. 2002, 188, 233.

(46) Lohitharn, N.; Goodwin, J. G. J. Catal. 2007, 245, 198.

(47) Yadav, G. D.; Nair, J. J. Microporous Mesoporous Mater. 1999, $33,1$.

(48) Aristizabal, B. H.; de Correa, C. M.; Serykh, A. I.; Hetrick, C. E.; Amiridis, M. D. J. Catal. 2008, 258, 95-102.

JP810465N 